\title{
INNOVATIVE PARADIGMS OF RESPONSIBLE CONSUMPTION IN ENSURING ENVIRONMENTAL SECURITY OF SOCIO-ECONOMIC SYSTEMS IN A PANDEMIC
}

\author{
Victoria S. Telyatnikova ${ }^{1}$, Anna $V$. Shokhnekh $^{1,{ }^{*}}$, Natalia $S$. Mushketova $^{2}$, and Ali G.B. Al Aayedi ${ }^{2}$ \\ ${ }^{1}$ Volgograd State Socio-Pedagogical University, Volgograd, Russia \\ ${ }^{2}$ Volgograd State University, Volgograd, Russia
}

\begin{abstract}
Innovative paradigms of responsible consumption represent a template, a model of renewal processes and environmentally friendly use of labor to create good in socio-economic systems, which corresponds to sustainable development and the society needs. The article examines a socioeconomic system that built on the cultural and ethical norms of actors (society, individual groups, people), taking into account their emotional state and the framework of legitimate rationality. The socioeconomic system defines a vector for improving the life quality in a balanced ecological environment as the basis for the moral component of responsible consumption in a civilized society. The socioeconomic paradigm quite rightly assigns an important place to moral obligations, social expectations and power relations that affect the behavior of economic actors, and, consequently, their responsible consumption of natural resources and goods produced. The analysis of social efficiency, sustainability of development, socio-economic and environmental balance of decisions made in a pandemic is becoming essential. It is important to note that the conditions of isolation, which are provided by the state, determine not only economic and social losses, but also cause psychological damage to the individual. The state, business and society must understand that a decrease in innovative interest and readiness for development during a pandemic will be massive. Currently, it is necessary to create conditions for the favorable adaptation of society to the use of forced measures, providing not only financial, but also mental support to prevent: decreased performance, emotional instability, the emergence of a state of tension and stress. In the process of making forecasts and socio-economic responsible consumption policy, it is important to define the concept, goals, objectives, principles, tools of reproduction environmental safety of economic and social system from the standpoint of economic, social, moral and moral parameters of entrepreneurial activity and labor.
\end{abstract}

\section{Introduction}

The formation and objective existence of socioeconomic relations in society are conditioned by the real factors of justice and the processes of natural life activity, which should be manifested in the equal access of every person to all the benefits of the earth, including clean products and a safe environment for health. In socioeconomic development, the basis is the tripartite relationship between ecology, economy and society. Ecology acts as a human habitat and a supplier of resources for satisfying needs, producing goods, accumulating wealth. The economy is considered as an economic unit of various sizes and levels (the economic system of society: region, city, village, a certain area (firm economics, health economics, education economics)), including individual households in which relations of relations occur during the production process, distribution, exchange, consumption. In socioeconomics, "society" as human resources that enter into relationships in the specificity of certain social communities reproduction (territorial, family) and individual social actors ${ }^{\mathrm{a}}$.

"Society" in relations with the environment and the economy characterizes the characteristics of the qualitative composition and behavior of social groups (communities) and actors of different levels (education, qualifications, health, family size and type, age, economic, territorial, official and other statuses (resources), level of legal awareness, business qualities, value features). Research shows that in a socioeconomic system, the determining vectors are the culture and the moral component of the subject (actor), whose actions are based on acquired knowledge, experience, emotions, and rationality. Also, the provisions of the constitution and legislative acts currently stimulate and support the development of society on the modern paradigm of many

\footnotetext{
a an active subject and participant of transformations, who is driven by his own motives (expectations, emotional experiences) and the corresponding experience
} 
socioeconomic systems development $[1,2]$. A civilized society is based on innovative production processes that ensure the vital activity of socio-economic systems, on a platform of continuous renewal, where special attention is paid to such environmentally risky industries as resource extraction, resource processing, resource communication.

\section{Discussions}

Innovative paradigms of responsible consumption in ensuring the environmental safety of socioeconomic systems are formed and become sustainable on the basis of science and technology achievements for effective expanded reproduction. In the process of making forecasts and socio-economic policies, it is important to analyze the environmental and social efficiency in ensuring sustainable development and social balance of decisions [3]. The ontology of responsible consumption innovative paradigm is manifested in the technical and technological scientific achievements of vital, but ecologically unsafe industries. The responsible consumption innovative paradigm is aimed at creating a perfect, qualitatively new, environmentally friendly product, on an updated production means of labor, which allows increasing production capacity and productivity of labor resources, as well as facilitating hard work. In socioeconomic systems, it is important to trace the relationship in the process of creating consumer goods that have use value. Undoubtedly, the consumer value is formed by the costs of endocrine components, including factors of production [4].

However, at present it is necessary to introduce the factor of group isolation conditions - conditions of a pandemic. Conditions of isolation lead to irritability emergence, discontent, mistrust of group members to each other, increased conflict in the group, aggressiveness [5]. In ecologically closed technical systems and unusual conditions of existence, a person, whether he is alone or in group isolation, is affected by such psychogenic factors as monotony, sleep rhythm mismatch and wakefulness, information limitation, life threat [6].

The study shows that the following factors of production in socioeconomic systems in a pandemic can be distinguished: 1) human resources (HR); 2) technical equipment (TE); 3) natural resources (NR); 4) institutional approach (Ins); 5) management organization (MO); 6) informational (Inf); 7) material resources (MR) "; 8) conditions of ecologically closed systems (CECS). All the presented indicators of the reproductive process in the socioeconomic system are reflected in the function (F), which characterizes the interaction of all factors (formula 1):

$$
Q=F(H R, T E, N R, \text { Ins, MO, Inf }, M R, C E C S)(1)
$$

It is important to note that the function of the reproduction process in the socioeconomic system refers to the factors of human activity in the system of ecological balance. It is necessary to highlight here that any production and reproduction activity in all systems will be an element of human labor, where a person acts from different positions, influencing and consuming the bio-system, but in the socio-system occupies many key roles, being:

1) entrepreneurial resources;

2) labor resources;

3) the consumer of goods as a result of production;

4) a third party with psychological emotions and attitude to the process and results of production;

5) the object of influence from positive or negative externalities in the production process of the economic system;

6) a state authority's representative;

7) an agent that implements many functions in the economic and socioeconomic systems.

Consequently, responsible consumption in the economic space will be the basis for ensuring environmental safety from the standpoint of human domination as an actor of the socioeconomic system.

It is also important to note that in the study of the socioeconomic space, it is advisable to take into account regional localization, which is included in the unity of constitutional principles, constitutional and legal institutions, norms governing the main socioeconomic aspects, environmental responsibility, the right of equal access to natural biodiversity and benefits [7].

It is obvious that in the context of a pandemic in many countries, the responsible consumption innovative processes in ensuring the environmental safety of socioeconomic systems have significantly slowed down, increasing the ecological balance risks, as well as determining the stagnation of the economy. It is obvious that the external conditions of the pandemic can play a decisive role in the stagnation of responsible consumption innovative paradigm, which is significantly dependent on investment flows. Investment flows finance the modernization of technologies and technological processes in the digital economy, including machine tools, machinery, equipment, personnel training [8]. The striving for a high level of environmental safety is manifested in the biotechnology development, depletion prevention and land resources reduction, increasing arable land, control over the use of food products made from genetically modified plants and microorganisms [9].

At present, responsible consumption innovative paradigms in socioeconomic systems are complicated by the conditions of a pandemic, however, they should be applied to the moral values of a civilized society, to which the metaphysical philosopher Immanuel Kant called almost 300 years ago: "Moral value should be seen only in the fact that an act is done from feeling debt" [10].

\section{Materials and methods}

The study used the methods of deduction, induction, analysis and synthesis, logic and analogy, as well as the method of a systems approach. 


\section{Research part}

Exploring responsible consumption innovative paradigms in ensuring environmental safety, it can be argued that the rapid development of this essence concept is diverse and is used in all spheres of society. The linguistics of innovative paradigms is defined in the meaning of a new sustainable template, updated, previously inapplicable, safe, modern. The responsible consumption innovative paradigm can be interpreted as the basis for the rapid growth of scientific knowledge: 1) on the scientific renewal of the means of labor; 2) during the transition to an environmentally friendly new technological order.

The objects of responsible consumption innovative paradigm of can be: socioeconomic needs; normative regulation and methodological support of the environmental safety of labor tools and the created benefits; material basic and circulating resources; labor resources and relationships; process-oriented technologies, operations; management processes; intellectual capital.

However, the study of responsible consumption innovative paradigm for the purpose of ensuring environmental safety is a systematic project for socioeconomic development (IPRSEES), aimed at improving and introducing new technical and technological means, taking into account the opportunities and risks of infrastructure development trends in a pandemic. In general, IPRSEES is a system of procedural actions aimed at new, corresponding to socio-economic needs and time, transformations in relation to: 1) legal regulation; 2) used material, intangible and labor resources; 3) professional relationships; 4) process-oriented technologies; 5) management production processes.

It is also important to note that IPRSEES in socioeconomic development is aimed at ensuring equal access to an ecologically clean environment, to the amount of healthy and safe food, of proper quality, necessary for a healthy lifestyle [11]. This is especially important in a pandemic.

The goal of IPRSEES in socio-economic development is to create new environmentally friendly and high-quality consumer goods at a reduced cost, ensuring profitable and responsible consumption.

The objectives of IPRSEES in socio-economic development are aimed at:

1) ensuring profitable innovative production, taking into account the trends of transition to a new technological structure and scientific and technological progress;

2) providing society with safe benefits based on environmentally friendly resources;

3) the stability of production processes in harmony with the needs of consumers, taking into account the provision of the necessary reserves and stocks;

4) responsible forecasting of the harmony of supply and demand in a pandemic;

5) responsible formation of strategic stocks of nonfood and food goods;

6) responsible development of normative legal acts regulating IPRSEES relations in socio-economic development;
7) the appropriate provision and consumption of the good to the established indicative parameters in the commodity markets in a pandemic.

The fulcrum and foundations of any theoretical and methodological templates, including IPRSEES in socioeconomic development, are the principles, namely [12]:

1) the principle of tax incentives for environmental innovations in resource-extracting, resource-processing, resource-communication industries in the context of sustainable development and the transition to a new technological one, taking into account scientific and technological progress;

2) the principle of responsible consumption under conditions of tax equilibrium in the markets for the production of goods;

3) the principle of responsible consumption tax optimization in the context of ensuring environmental protection in the process of creating benefits by resource-extracting, resource-processing, resourcecommunication industries;

4) the principle of innovative simplification of heavy processes in resource-extracting, resource-processing, resource-communication industries;

5) the principle of tax incentives for a careful attitude to resources in conditions of resource scarcity and scarcity;

6) the principle of territorial resource potential of innovative reserve capabilities in resource-extracting, resource-processing, resource-communication industries;

7) the principle of innovative state preferences for responsible consumption and provision of resourceextracting, resource-processing, resource-communication industries;

8) the principle of tax and non-tax incentives for innovative updates in the responsible consumption of resource-extracting, resource-processing, resourcecommunication industries to create benefits in a pandemic.

The implementation of the innovative paradigm of responsible consumption is subject to numerous adverse factors, where the most significant can be classified as:

1) macroeconomic, characterized by a decrease in investment attractiveness in innovative transformation;

2) technological, characterized by a significant lag in terms of the technological structure of the national production base;

3) agro-ecological, characterized by complex or abnormal climatic and natural changes, as well as a manmade state of emergency;

4) foreign trade, characterized by unfavorable changes in the market environment, caused by an increase / decrease in barriers, as well as applied measures of state influence.

Specifying the internal unfavorable factors of responsible consumption use in ensuring environmental safety, intensified by the conditions of the pandemic, one can single out such as:

1) low innovative activity in the production of goods;

2) lack of competent labor resources, including entrepreneurial; 


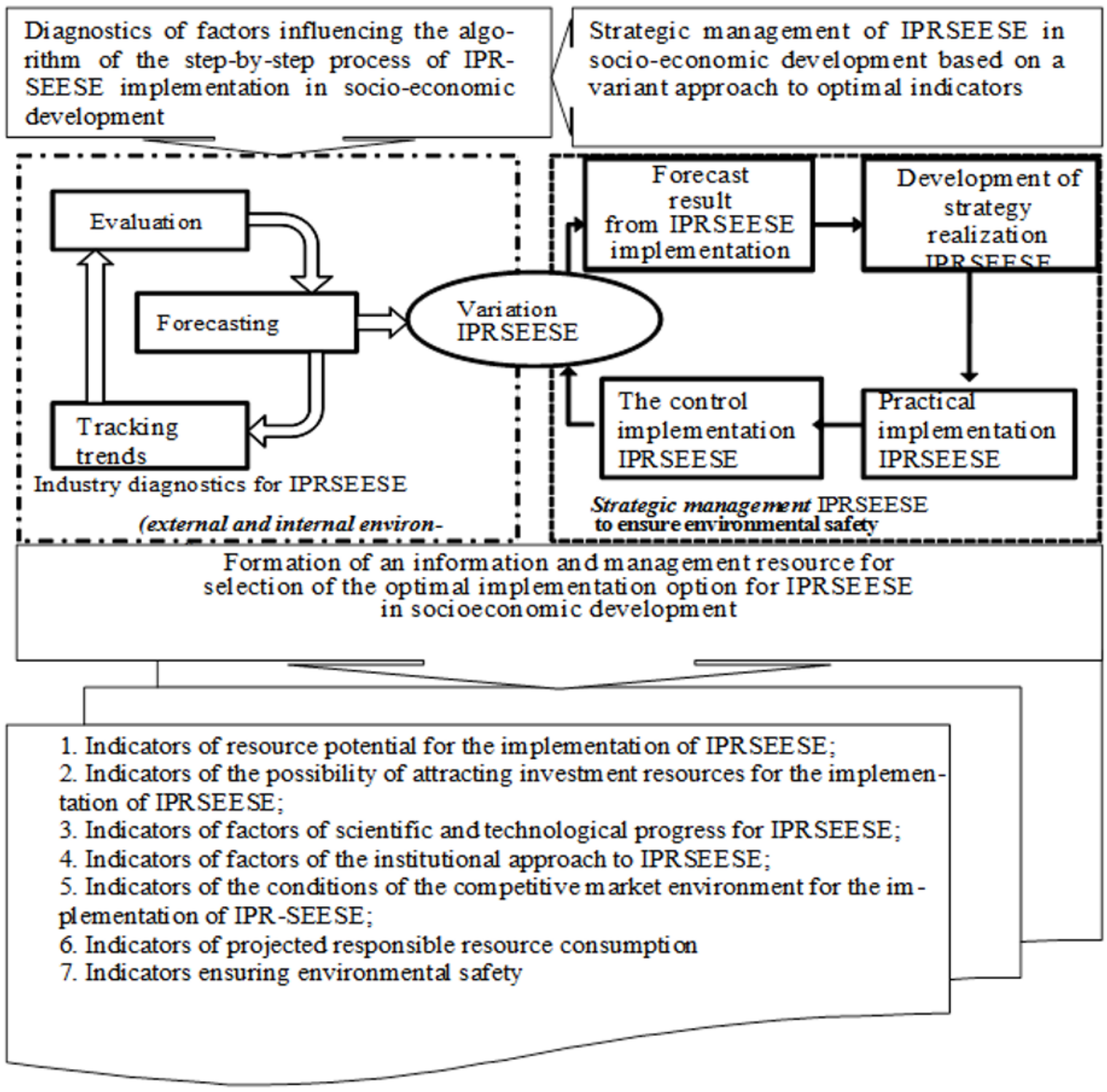

Fig. 1. Algorithm of the step-by-step process of IPRSEESE implementation.

3) a high spread in the levels of wages and quality of life of the population;

4) low personal position in relation to the conditions for ensuring environmental safety;

5) lack of proper national environmental control in the country;

6) free access to the extraction of natural resources in a specific area;

7) the absence of a lean economy in the system of responsible education;

8) wasteful attitude, loss of regional value attitudes towards natural resources due to their availability and abundance in a particular territory [13].

The study shows that the depletion of natural resources determines the need for the introduction of innovative industries that will increase the depth of their processing. Of course, responsible consumption requires public investment to replace morally and physically obsolete means of labor in resource-extracting, resourceprocessing, resource-communication industries [14].
Therefore, it is necessary to identify possible classification directions for the introduction of innovations in the process of implementing IPRSEES.

1. For IPRSEESE objects: business entities; production systems, including fixed assets; technological processes; consumer goods production management systems; infrastructure.

2. According to the level of production innovative safety coverage of processes IPRSEESE: partial, elemental, complex.

3. According to the purpose of IPRSEESE application: implementation of a lean economy; to ensure environmental safety.

4. By the nature of technological changes in the process of IPRSEESE implementation: catching up; developing technological; ahead of time; forced in a pandemic.

5. By subjects of the initiator of the implementation of IPRSEESE: state programs; public policy; world (sectoral) development course; by the decision of the 
owners; by decision of the hired management; according to the proposals of the labor collective.

6. By funding sources IPRSEESE: government subsidies; depreciation funds; own funds; borrowed capital; investments; complex financial resources.

7. On the justification of management decisions for the implementation of IPRSEESE: justified implementation of the environmental program; forced, stimulating or massive implementation of an environmental program.

8. According to the technology of IPRSEESE implementation: implementation of the environmental program on its own or through outsourcing.

\section{Final part}

Under the conditions of different IPRSEESE implementations, the following problems may appear in the use of specific tools, namely: problems in resource capabilities; problems in competent personnel; problems in models and technologies; problems in free physical movement in a pandemic.

One of the incentives for the state policy for the implementation of IPRSEESE in the regions can be a stimulating fund formed for budgetary injections and deductions of the environmental tax. Undoubtedly, the main indicators of the need to implement responsible consumption within the IPRSEESE framework are resource requirements and opportunities, confirmed by quantitative and qualitative targets and benchmarks. The phased application of IPRSEESE implementation procedures makes it possible to identify problems at each step of making management decisions within a given time interval and a system of indicators. An algorithm for the step-by-step process of implementing IPRSEESE is shown in Figure 1.

The possible variance of the IPRSEESE implementation is a set of renewal measures that are gradually distributed over time, are in a causal relationship with each other for resource conservation. On the basis of institutional and competitive superiority, the participants - the subjects of the IPRSEESE implementation - set indicators, defining the criteria for the efficiency of responsible consumption. However, the state, investors, the market, the technology community provide favorable conditions for the implementation of IPRSEESE.

\section{Conclusion}

Making a conclusion, it is important to note that in the process of implementing IPRSEESE, it is advisable to provide institutional stimulation of socioeconomic development, which can take place on the basis of an agreement between the authorities, business and society as a set of activities taking place in different time ranges. The ranges run in a causal relationship with innovative high-tech production focused on resource conservation and competitive advantages. However, the complexity of implementing innovative paradigms as models of responsible consumption in ensuring the environmental safety of socio-economic systems in a pandemic requires the use of market mechanisms, institutional approaches, as well as direct and indirect incentives. The formation of the IPRSEESE implementation tools should also be based on the priorities of the nation - ensuring environmental safety, which are established in accordance with legal acts that determine the conditions for the functioning of the country's economy and its individual industries, which is provided by financial resources of the macro- and meso-level.

However, at present, anti-epidemic measures aimed at restrictive measures in accordance with epidemiological laws significantly reduce the implementation of the innovative paradigm of responsible consumption in ensuring environmental safety. All forces of society are aimed at ensuring safety and restoring human health as an active and main unit of society. it is obvious that in the context of identifying infected people and separating them from healthy individuals in order to prevent mass morbidity, it significantly reduces the level of readiness for the implementation of any innovative initiatives.

It is in such an epidemiological situation that it is important to substantiate and apply tax instruments in the implementation of IPRSEESE, which optimizes the reliable prevention of internal and external threats, taking into account state forecasts of socio-economic development. Tax instruments that stimulate the implementation of IPRSEESE will provide explicit and implicit trade-offs between competitive and innovative economies by the doctrine of institutional directions.

The reported study was funded by the Russian Foundation for Basic Research grant No. 19-010-00985 A. "Development of innovative and investment policy as a concept of strategic economic security of agricultural organizations in the conditions of the modern technological transformation".

\section{References}

1. Etzioni, Socioeconomics: further steps, Per. M. S. Dobryakova, Economic sociology, 3, 1, 65-71 (2002)

2. Etzioni, Howard a New Socio-Economic Paradigm, Socio-Economic Review, 1, 105-118, (2003)

3. O. A. Alekseev Cost contradiction of entrepreneurship: system and value-motivational foundations of resolution and creation, European Social Science Journal, 3, 7-12 (2015)

4. O. V. Inshakov, D. P. Frolov Economic space and spatial economy, ENSR, 4, 31, 58-70 (2005)

5. N. N. Lepeshinsky, Moderating effects of social support in conditions of relative group isolation, Social psychology and society, 3, 54-64 (2011)

6. S. Chertovikov Stressful factors in isolation, Problems of modern pedagogical education, 60, 1, 485-489 (2018)

7. V. E. Chirkin About the socio-economic paradigm (models) The Constitution of Russia in 1993, The Constitutional and municipal law, 12, 27 - 32 (2018) 
8. L. I. Pronyaeva Managerial accounting and innovation and investment policy in the agroindustrial complex, Economic analysis: theory and practice, 19 (2008)

9. On the National Security Strategy of the Russian Federation until 2020, (Decree of the President of the Russian Federation of 12.05.2009 N 537) (2009)

10. I.Kant, Criticism of Pure Reason, Simferopol: "Renome", 528 (1998)

11. The doctrine of Food Security. Approved by Decree of the President of the Russian Federation, (120 of January 30, 2010) (2010)

12. Y.V. Melnikova, A.V.Shokhnekh, Forming the Policy of Insurance of Innovative and Investment Activities of Agricultural Organizations as a Concept-Strategy of Provision of Economic and Food Security, Lecture Notes in Networks and Systems, 87, 809-816 (2020)

13. Y.V.Melnikova, E.A.Posnaya, B.A. Bukach, A.V.Shokhnekh, S.V.Tarasenko, Defining Key Determinants of the Strategic Economic Security of the Agro-Industrial Complex in Terms of Stabilizing Political Course, E3S Web of Conferences, 161, 01105 (2020)

14. H. Abu Ezza, A.V. Shokhnekh, V.S. Teklanika, N.S. Mushketova, Quality parameters of information systems for business in the context of digital transformations, E3S Web of Conferences, 208, 03059 (2020). 